\title{
An investigation on the behavior and morphology of sulphanilamide crystallization in different nucleation conditions
}

\author{
Smita Shivraj Dasari, Ajit Kumar Tallapaka and Jyothi Thati (10)
}

\begin{abstract}
Background: Crystallization is used as a purification process in majority of the industries such as pharmaceuticals, food products, chemicals, catalysts, and cosmetics. Crystallization of active pharmaceutical ingredients is carried out to increase the dissolution rate and attain sufficient bioavailability in pharmaceutical industries. It can also enhance the flow properties and drug dosage control of the active pharmaceutical ingredients.

Single crystals give us a lucid understanding of the intrinsic properties of a material. A material made up of many crystals will have grain boundaries which do not allow us to measure properties such as thermal and electrical resistance effectively. Single crystals will not have defects or impurities in them. Thus, help us in making comparisons with other materials and contribute to a better understanding of particular behaviors. Therefore, it is important to investigate the growth of single crystals.

Sulphanilamide is a sulpha class drug used as an intermediate and starting material for the production of various drugs. It is an antibacterial agent and is often used in pharmaceutics and cosmetics. In this study, we wanted to obtain sulphanilamide crystals by two different crystallization methods and compare the results gathered.

Sulphanilamide usually crystallizes in the form of needles, thus is ideal for the purpose of this study. In this work, crystallization of sulphanilamide was carried out by cooling method and solvent evaporation method. In Cooling method as temperature was brought down the crystals separated out. On the other hand, in solvent evaporation method, the solvent evaporated leaving behind the crystals. The process parameters that varied included stirring rate of the solution at a constant temperature, concentration of the solute in a constant volume of solvent, solvent systems chosen-acetone, methanol and ethanol, and time allowed for crystallization.

(Continued on next page)
\end{abstract}

\footnotetext{
* Correspondence: jyothithati@ouct.ac.in

Department of Chemical Engineering, University College of Technology (A),

Osmania University, Hyderabad-7, Hyderabad, India
}

\section{Springer Open}

(c) The Author(s). 2020 Open Access This article is licensed under a Creative Commons Attribution 4.0 International License, which permits use, sharing, adaptation, distribution and reproduction in any medium or format, as long as you give appropriate credit to the original author(s) and the source, provide a link to the Creative Commons licence, and indicate if changes were made. The images or other third party material in this article are included in the article's Creative Commons licence, unless indicated otherwise in a credit line to the material. If material is not included in the article's Creative Commons licence and your intended use is not permitted by statutory regulation or exceeds the permitted use, you will need to obtain permission directly from the copyright holder. To view a copy of this licence, visit http://creativecommons.org/licenses/by/4.0/. 
(Continued from previous page)

Results: Crystals were obtained under the varying conditions. Characterization of the crystals formed was carried out using X-ray diffraction method, scanning electron microscopy, and differential scanning calorimetry. The size and morphology of the crystals formed was observed and the results were compared. It was found that the crystals obtained from using methanol as solvent, with high concentration of solute, gave the most uniform and large-sized cubic crystals under solvent evaporation method. The surface of the crystal was also seen to be smooth with welldefined edges as shown in the SEM images. Stirring reduced the size of crystals formed, and longer time of crystal formation resulted in larger crystals. Solvent evaporation method gave more uniform crystals compared to cooling method.

Conclusion: This study gives us an understanding of how each parameter affects crystal growth. Thus, optimum conditions for crystal growth can be determined.

Keywords: Crystallization, Crystal growth, Sulphanilamide, Cooling crystallization, Solvent evaporation

\section{Background}

Physical properties of the crystals can be altered by varying the crystal lattice. Size alteration mainly includes agglomeration where small crystals adhere to form bigger particles. Various physical properties such as flow properties can be modified during the crystallization process. Crystal habit can be modified by optimizing the process parameters, like stirring rate, selection of solvent, $\mathrm{pH}$, temperature, etc., which affect the physico-chemical properties (solubility, dissolution rate, bioavailability, and stability) and micrometric properties (bulk density, flow property, compressibility) of the crystals $[1,2]$.

In crystallization, the solute separates out from the solution as solid. Thus, there is a phase change involved. This change depends on the solubility of solute in the system, which is related to temperature. Crystallization of active pharmaceutical ingredients is carried out in pharmaceutical industries to increase the dissolution rate and reach sufficient bioavailability. It can also enhance the flow properties and drug dosage control. The complex behavior of industrial crystallizers remains elusive. One of the reasons for this is the lack of appropriate tools for measurement and monitoring of crystallization processes. On the other hand, demands for consistent product quality, purity, and crystal size are ever increasing and are therefore creating a large interest in crystallization research. The aim of all crystallization processes is to create a supersaturated solution or melt. The supersaturation becomes the driving force under which new crystals are formed and existing crystals grow. For majority of the substances, solubility increases with temperature. Any solute added in the soluble region dissolves. On the other hand, in the metastable stage, existing crystals will grow but new crystals are not formed. On cooling further, we enter the labile region where spontaneous formation of new crystals; that is nucleation occurs [3, 4].

The crystal growth rate is the rate at which the size of the crystal increases. The nucleation rate is defined as the number of new crystals formed per unit time and volume of suspension. Secondary nucleation can take place at low supersaturation when crystals are already present. Small parts of the existing crystals are washed off and form new nuclei that can grow. Several methods are available for crystallization. The methods that are used for the purpose of this report are solvent evaporation method and cooling crystallization. In solvent evaporation, the solute is dissolved at a constant temperature and pressure, in one solvent in which it is moderately soluble, or in a mixture of two solvents-one of which is a good solvent or cosolvent, and the other which is an anti-solvent, until saturation is achieved. The solvent system is then allowed to evaporate at room temperature, leaving behind the crystals. In cooling crystallization, a saturated solution of the solute is formed in a solvent system, at an elevated temperature just below the boiling point of the solvent system, then allowed to cool, forming crystals [5].

Sulphanilamide has a myriad of uses in the pharmaceutical industry and thus was used as a model drug in this study. It has a chemical formula of $\mathrm{C}_{6} \mathrm{H}_{8} \mathrm{~N}_{2} \mathrm{O}_{2} \mathrm{~S}$ (IUPAC name 4-aminobenzenesulfonamide) with a molecular weight of $172.202 \mathrm{~g} / \mathrm{mol}$. It is white in color and has a melting point of $165.5^{\circ} \mathrm{C}$. It has a $\mathrm{pH}$ range of $5.8-6.1$, density of 1.08 at $25{ }^{\circ} \mathrm{C}$. It is an antibacterial agent and often used in pharmaceutics and cosmetics.

In 2019, Rasmuson et al. investigated the growth of single salicylamide crystals in non-stirred experiments. In their study, it was discovered that the solvent system influenced the growth rate and supersaturation. The growth kinetics was also strongly affected by temperature. We expected to see a similar relationship between temperature, solvent system, and crystal structure in this study [6-8].

\section{Methods}

Chemicals Sulphanilamide extra pure (99\% pure), ethanol (purity 99.7\%), heptane (purity 99\%), toluene (purity 99 to $99.4 \%$ ), acetone (purity 99\%), and methanol (purity 
Table 1 Summary of the results obtained

\begin{tabular}{llll}
\hline Solvent evaporation method & & & \\
\hline Concentration (g sulphanilamide/ml solvent) & Stirring rate $(\mathrm{rpm})$ & Time $(\mathrm{h})$ & Result \\
\hline Methanol solvent system & & & \\
Irrespective of the concentration, no needles or crystals & were observed when the solution was evaporated for $12 \mathrm{~h}$ & Needles \\
0.04 & 0 & 24 & Needles \\
0.05 & 0 & 24 & Small cube-shaped crystals \\
0.058 & 0 & 24 & Small cube-shaped crystals \\
0.065 & 0 & 24 & Short needles \\
0.04 & 0 & 48 & Long needles \\
0.05 & 0 & 48 & Cube-shaped crystals \\
0.058 & 0 & 48 & Large crystals \\
0.065 & 0 & 48 & Needles \\
0.04 & 0 & 72 & Needles \\
0.05 & 0 & 72 & Large cube-shaped crystals \\
0.058 & 0 & 72 & Large cube-shaped crystals
\end{tabular}

Irrespective of the concentration and time, no needles or crystals were observed when the solution was evaporated with a stirring speed of 100 rpm Ethanol solvent system

Irrespective of the concentration, no needles or crystals were observed when the solution was evaporated for $12 \mathrm{~h}$

$\begin{array}{llll}0.019 & 0 & 24 & \text { No crystals } \\ 0.024 & 0 & 24 & \text { No crystals } \\ 0.032 & 0 & 24 & \text { Needles } \\ 0.041 & 0 & 24 & \text { Needles } \\ 0.019 & 0 & 48 & \text { Very small needles } \\ 0.024 & 0 & 48 & \text { Very small needles } \\ 0.032 & 0 & 48 & \text { Small needles } \\ 0.041 & 0 & 48 & \text { Very small crystals }\end{array}$

Irrespective of the concentration and time, no needles or crystals were observed when the solution was evaporated with a stirring speed of 100 rpm Solvent evaporation method

Concentration(g sulphanilamide/ml solvent) $\quad$ Stirring rate(rpm) $\quad$ Time (h) Result

Acetone solvent system

Irrespective of the concentration, no needles or crystals were observed when the solution was evaporated for $12 \mathrm{~h}$ with and without stirring

$\begin{array}{llll}0.1016 & 0 & 24 & \text { Needles } \\ 0.1383 & 0 & 24 & \text { Needles } \\ 0.1826 & 0 & 24 & \text { Small cuboid } \\ 0.218 & 0 & 24 & \text { Small cuboi } \\ 0.102 & 100 & 24 & \text { Needles } \\ 0.138 & 100 & 24 & \text { Needles } \\ 0.183 & 100 & 24 & \text { Needles } \\ 0.218 & 100 & 24 & \text { Very small crys } \\ \text { Cooling method } & & & \text { No crystals } \\ \text { Methanol solvent system } & & & \text { No crystals } \\ 0.04 & 0 & 4 & \text { No crystals } \\ 0.05 & 0 & 4 & 4 \\ 0.058 & 0 & & \end{array}$


Table 1 Summary of the results obtained (Continued)

\begin{tabular}{llll}
\hline Solvent evaporation method & & & \\
\hline Concentration (g sulphanilamide/ml solvent) & Stirring rate $(\mathrm{rpm})$ & Time $(\mathrm{h})$ & Result \\
\hline 0.065 & 0 & 4 & Very small crystals \\
0.04 & 0 & 6 & No crystals \\
0.05 & 0 & 6 & No crystals \\
0.058 & 0 & 6 & Very small crystals \\
0.065 & 0 & 6 & Very small crystals
\end{tabular}

Irrespective of the concentration and time, no needles or crystals were observed when the solution was cooled with a stirring speed of 100 rpm

Ethanol solvent system

No needles or crystals were observed

Acetone solvent system

No needles or crystals were observed

99.6\%) were purchased from Molychem and used with no further purification. The solvent evaporation apparatus consists of a hot plate with temperature probe, a magnetic stirrer, $100 \mathrm{ml}$ beakers, and magnetic beads. Aluminum foil with equal sized holes is used to cover the beakers to allow for uniform slow evaporation. Every foil cap had 18-20 holes of diameter $1 \mathrm{~mm}$ with an inter hole distance of $5 \mathrm{~mm}$. All the beakers used were of uniform size. The cooling method apparatus consist of a cooling bath, $100 \mathrm{ml}$ beakers covered with aluminum foil to prevent solvent from evaporating when heated, a heating plate and a mechanical stirrer.

\section{Solvent evaporation}

Twenty milliliters of solvent was taken in a $100 \mathrm{ml}$ beaker and kept for stirring at $700 \mathrm{rpm}$, at $25{ }^{\circ} \mathrm{C}$ on a hot plate. Once the system is stable, sulphanilamide was

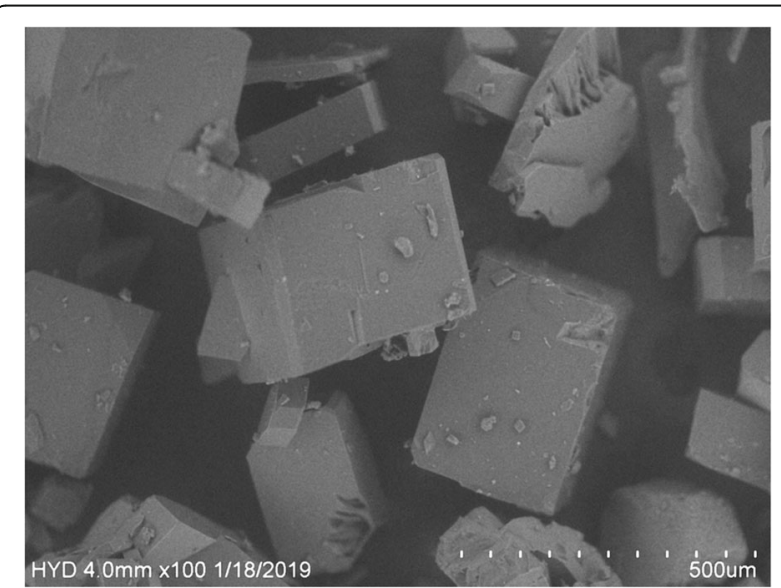

Fig. 1 SEM image of $0.065 \mathrm{~g} / \mathrm{ml}$ of solute in methanol obtained by solvent evaporation method carried out for $48 \mathrm{~h}$ with no stir $(\times 100)$ weighed and added. Once a clear solution was formed, the beaker was removed and covered with aluminum foil with holes, and left to evaporate for a given time at room temperature at the desired stirring speed. After the time was elapsed, the foil was removed and any crystals that were formed were collected and sent for analysis. The process was repeated for different time periods, different concentrations of solute and different solvent systems.

\section{Cooling method}

Required concentration of clear solution at $50{ }^{\circ} \mathrm{C}$ was taken in a beaker and placed in a cooling bath. The temperature was brought down to $5{ }^{\circ} \mathrm{C}$. The solution was then allowed to cool at this temperature for either 4 $\mathrm{h}$ or $6 \mathrm{~h}$ with the desired stirring speed. After the time elapsed, the sample was removed. Any crystals formed were collected by filtration and sent for analysis. The

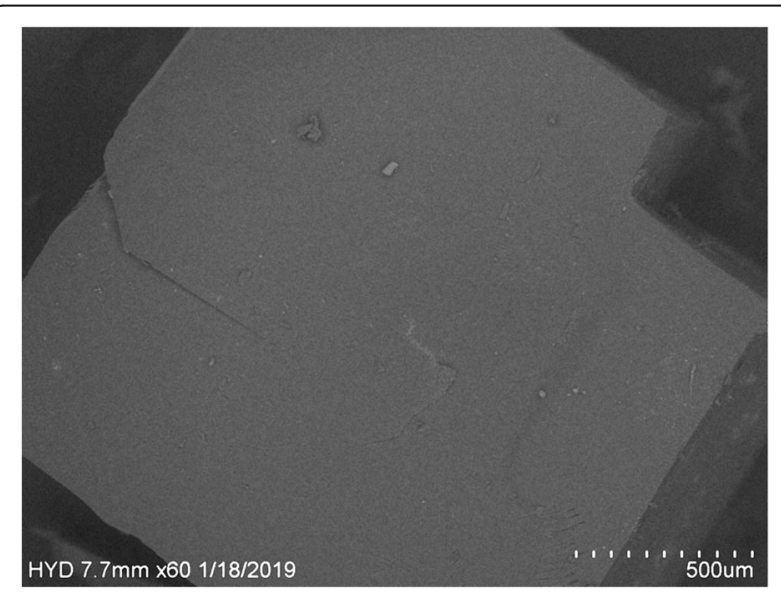

Fig. 2 SEM image of $0.65 \mathrm{~g} / \mathrm{ml}$ of solute in methanol obtained by solvent evaporation method carried out for $72 \mathrm{~h}$ with no stir $(\times 60)$ 


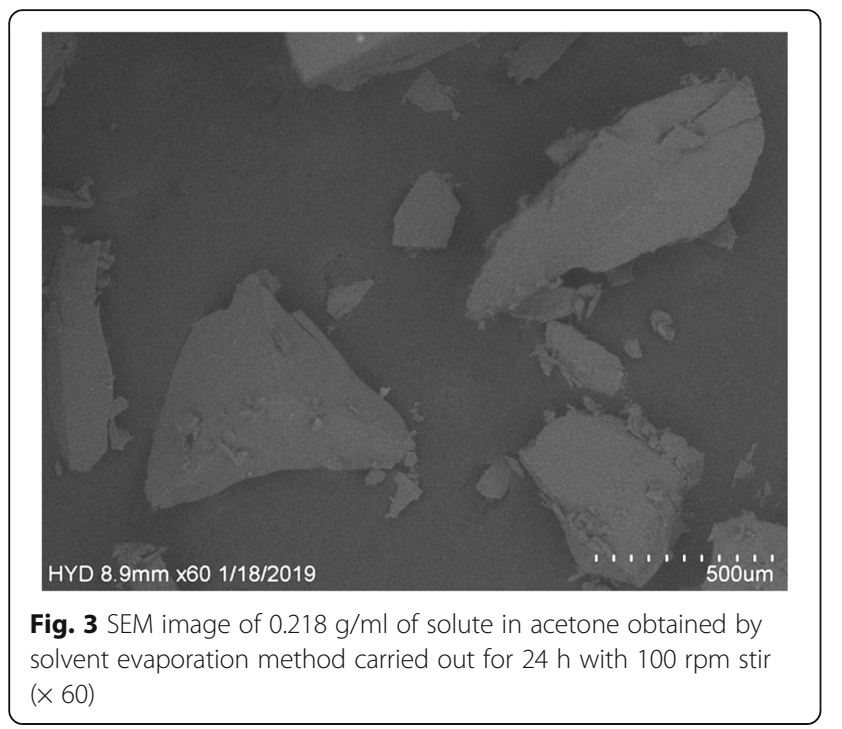

previous steps were repeated for different concentrations of solutes and different solvents. The samples collected were sent for SEM, XRD, and DSC analysis.

The following concentrations of solutions were taken g/ $\mathrm{ml}$ where $\mathrm{g}$ denotes weight of the solute sulphanilamide and $\mathrm{ml}$ represents the volume of solvent:

Acetone : $0.218,0.1826,0.1383,0.1016$

Methanol : 0.065, 0.058, 0.05, 0.04

Ethanol : 0.041, 0.032, 0.024, 0.019

Time for solvent evaporation : $12 \mathrm{~h}, 24 \mathrm{~h}, 48 \mathrm{~h}$ (only in the case of ethanol and methanol systems) and $72 \mathrm{~h}$ (only in case of methanol systems)

Time for cooling method: $4 \mathrm{~h}$ and $6 \mathrm{~h}$
Stirring speeds : $0 \mathrm{rpm}$ and $100 \mathrm{rpm}$.

\section{DSC}

To notice how the crystals have melted as well as to check whether any reaction has occurred between the solute and the solvent, differential scanning calorimetry scans of the crystals obtained were taken and compared. Here, the samples were heated in an inert environment containing Nitrogen with a gas flow of $50 \mathrm{ml} / \mathrm{min}$ on an aluminum crucible. The temperature was increasing at the rate of $10{ }^{\circ} \mathrm{C}$ per minute within a range of $26{ }^{\circ} \mathrm{C}$ to $200{ }^{\circ} \mathrm{C}$.

\section{X-ray diffraction}

The X-ray diffraction was carried out in a copper tube (Cu-K1) with X-rays having a wavelength of $1.506 \AA$, at a voltage of $40 \mathrm{mV}$ and a current of $30 \mathrm{~mA}$.

\section{SEM analysis}

The surface morphology was compared using scanning electron microscopy (Table 1).

\section{Results}

In solvent evaporation method, all crystals obtained were of uniform size. It was found that no crystals were formed for ethanol systems with any concentration of solute when the solutions were left to evaporate for time periods of $12 \mathrm{~h}$ and $24 \mathrm{~h}$. However, at lower concentrations $(0.019 \mathrm{~g} / \mathrm{ml}$ and $0.024 \mathrm{~g} / \mathrm{ml})$, very small needles were formed after evaporation for $48 \mathrm{~h}$ when left without stirring and very small crystals were formed only at the highest concentration of

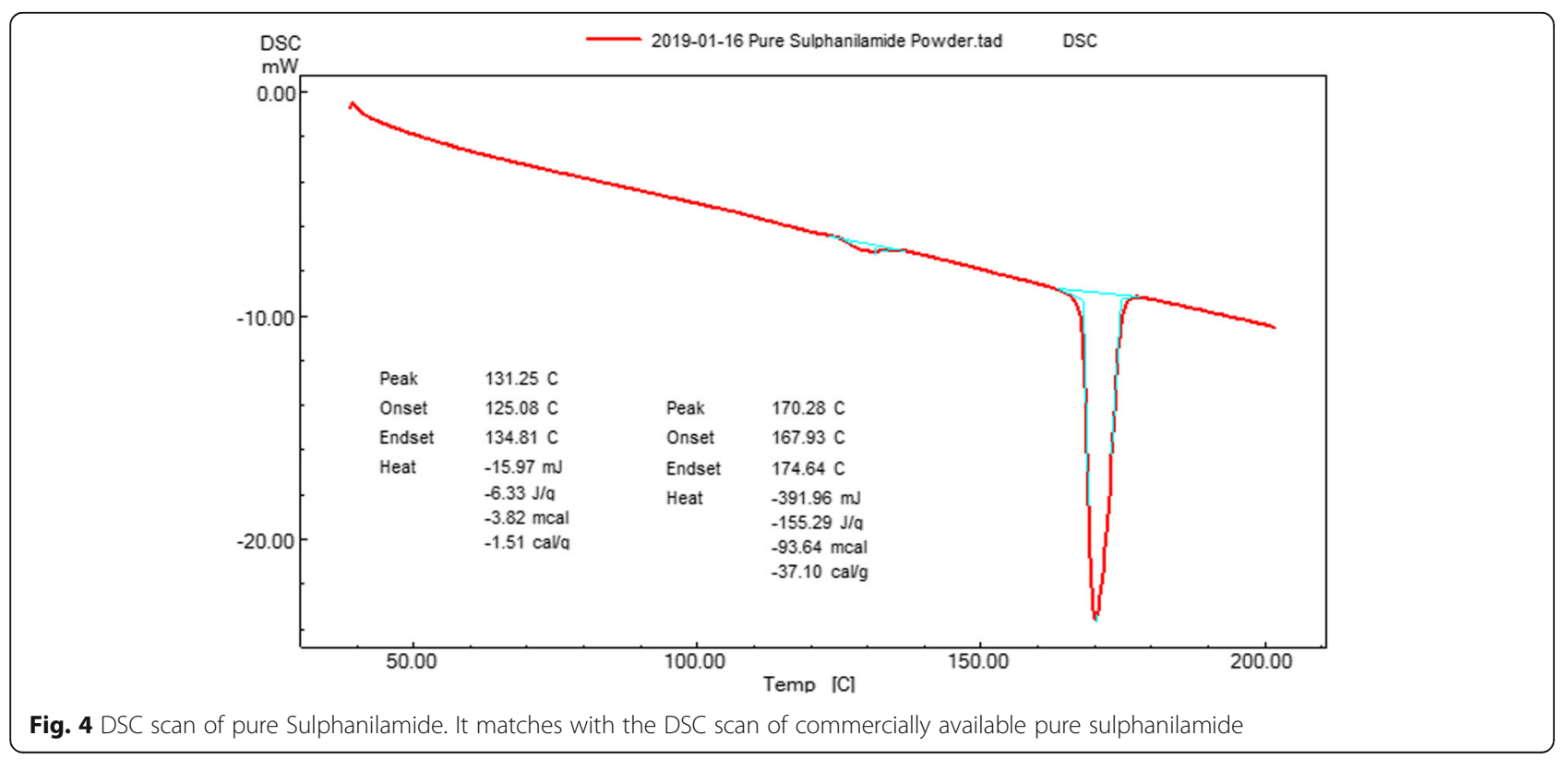




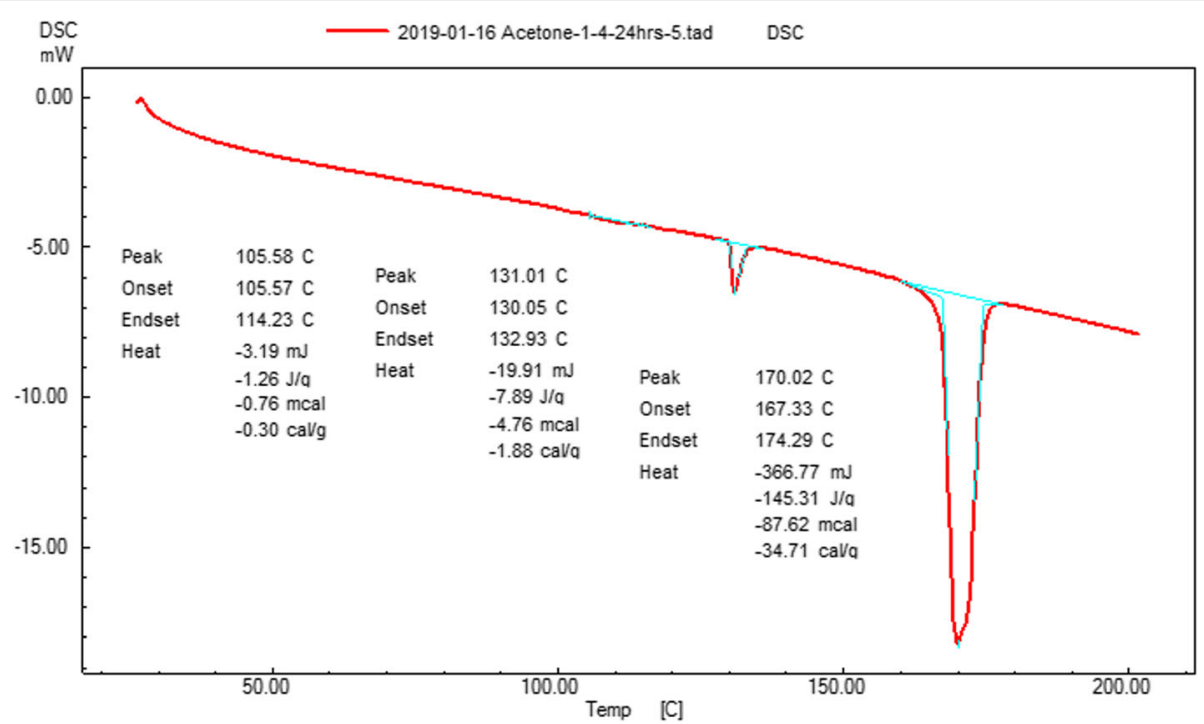

Fig. 5 DSC scan of crystals formed from $0.218 \mathrm{~g} / \mathrm{ml}$ of solute in acetone obtained from solvent evaporation method carried out for $24 \mathrm{~h}$ with stir. The peak at $108{ }^{\circ} \mathrm{C}$ shows the crystal losing intrinsic solvent

$0.041 \mathrm{~g} / \mathrm{ml}$ in the ethanol system. Similarly for methanol systems no crystals were formed in the first $12 \mathrm{~h}$ but when left for $24 \mathrm{~h}$, at lower concentrations $(0.04$ $\mathrm{g} / \mathrm{ml}$ and $0.05 \mathrm{~g} / \mathrm{ml}$ ) needles were formed, and at higher concentrations $(0.058 \mathrm{~g} / \mathrm{ml}$ and $0.065 \mathrm{~g} / \mathrm{ml})$ small crystals were formed as shown in Fig. 1. When the cubical crystals in the methanol system were left for $48 \mathrm{~h}$ and $72 \mathrm{~h}$, crystal growth was observed as shown in Fig. 2. Even when a smaller amount of solute was used in the methanol system with no stir, well defined crystals were observed. The largest crystals formed in methanol systems after $72 \mathrm{~h}$ had dimensions $4 \times 5 \times 2 \mathrm{~mm}^{3}$. For acetone systems, small needles were formed at low concentrations $(0.1016 \mathrm{~g} /$ $\mathrm{ml}$ and $0.1383 \mathrm{~g} / \mathrm{ml}$ ) when left for $24 \mathrm{~h}$ for the solvent to evaporate, and small cuboidal crystals were observed at higher concentrations $(0.1826 \mathrm{~g} / \mathrm{ml}$ and $0.218 \mathrm{~g} / \mathrm{ml})$. When acetone systems were placed for evaporation with stirring at $100 \mathrm{rpm}$ for $24 \mathrm{~h}$ very small needles were formed only at the concentration of $0.218 \mathrm{~g} / \mathrm{ml}$ as shown in Fig. 3. The largest crystals formed in acetone systems had dimensions $2 \mathrm{mmx} 1 \mathrm{mmx} 1 \mathrm{~mm}$. The crystals formed in ethanol systems were irregular in shape and were very small.

In Cooling method no crystallization was observed for acetone and ethanol systems. In methanol systems when $0.65 \mathrm{~g} / \mathrm{ml}$ of sulphanilamide was allowed to cool for $4 \mathrm{hrs}$ and $6 \mathrm{hrs}$, very small irregularly shape crystals were

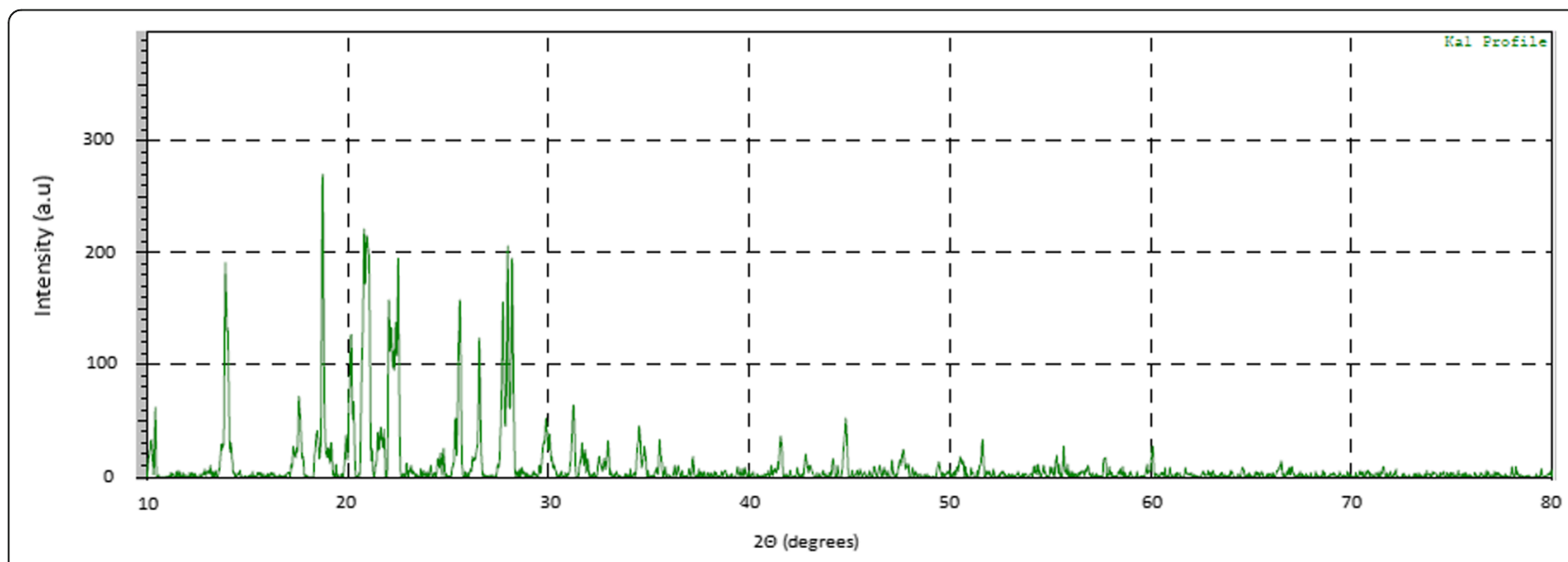

Fig. 6 XRD scan of pure sulphanilamide 


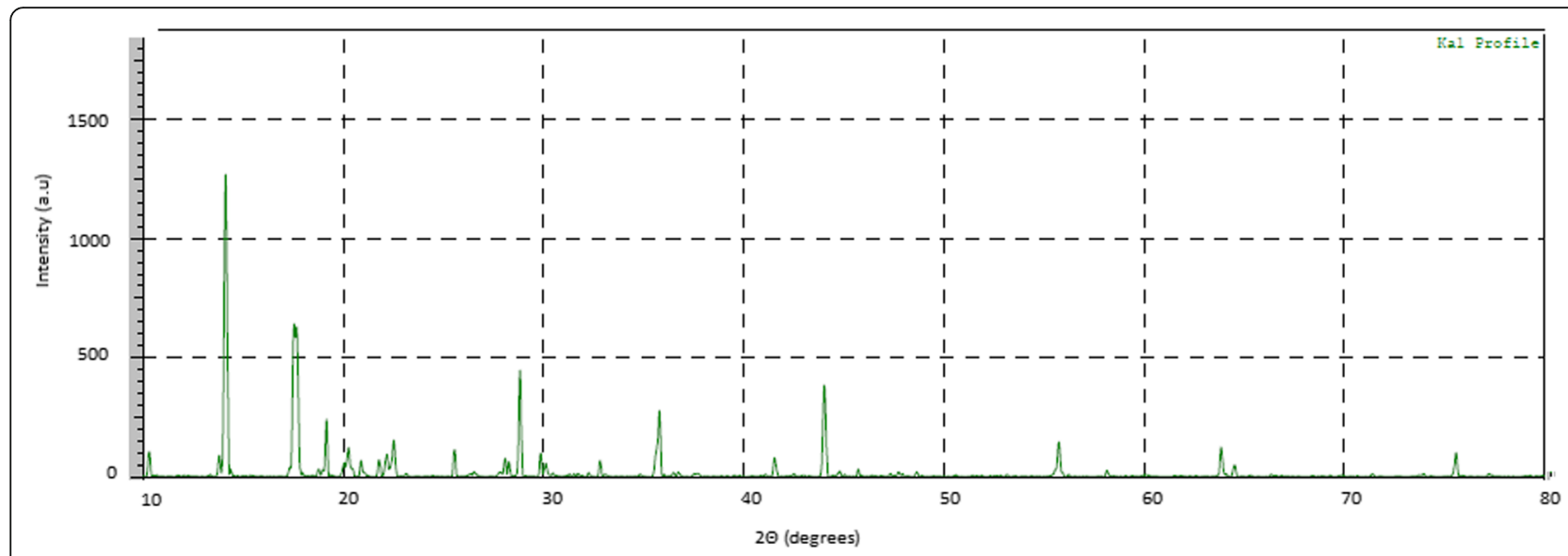

Fig. 7 XRD scan of crystals formed from $0.058 \mathrm{~g} / \mathrm{ml}$ of solute in methanol obtained by solvent evaporation method carried out for $48 \mathrm{~h}$ with no stir

formed with and without stirring. At the low concentrations of $0.04 \mathrm{~g} / \mathrm{ml}$ and $0.05 \mathrm{~g} / \mathrm{ml}$, no crystals were formed.

From the DSC scans shown in Figs. 4 and 5, it can be concluded that the crystals obtained were pure and free of any contamination. The crystal behavior under changing temperature is also seen in these scans.

In order to find the crystallite size, the XRD graphs of the crystals were obtained and the Debye-Scherrer formula was used:

$$
\tau=\frac{k \lambda}{\beta \cos \Theta}
$$

$$
\begin{aligned}
\text { Where } \mathrm{\tau} & =\text { size of crystal grain, } k \\
& =\text { shape factor taken as } 0.9, \lambda \\
& =\mathrm{X} \text { - ray wavelength taken as } 1.5406 \AA, \\
& \Theta=\text { Braggs angle }
\end{aligned}
$$

It can be observed that the width of the peaks vary in different samples due to the way the crystal lattice shape and structure changes (Figs. 6 and 7). In some cases, a zero error exists due to rotation of crystal plane, thus the peaks shift more toward a higher two-theta angle value (Figs. 8 and 9). Calculating grain size for the given compounds using Debye-Scherrer formula for the samples taken in Table 2, we found the sizes of crystallites as shown in Table 3. In Table 2, few of the crystal samples obtained by solvent evaporation method that were used to compare crystallite size are shown.

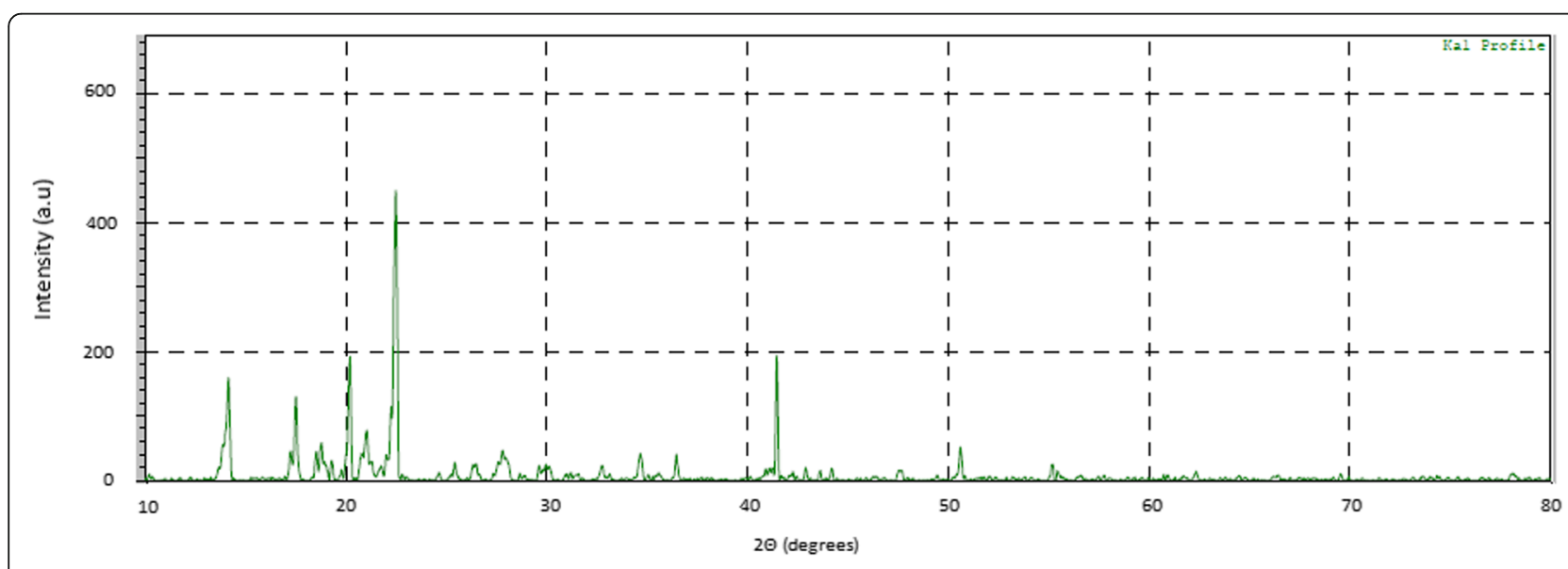

Fig. 8 XRD scan of crystals formed from $0.065 \mathrm{~g} / \mathrm{ml}$ of solute in ethanol obtained by solvent evaporation method carried out for $48 \mathrm{~h}$ with no stir 


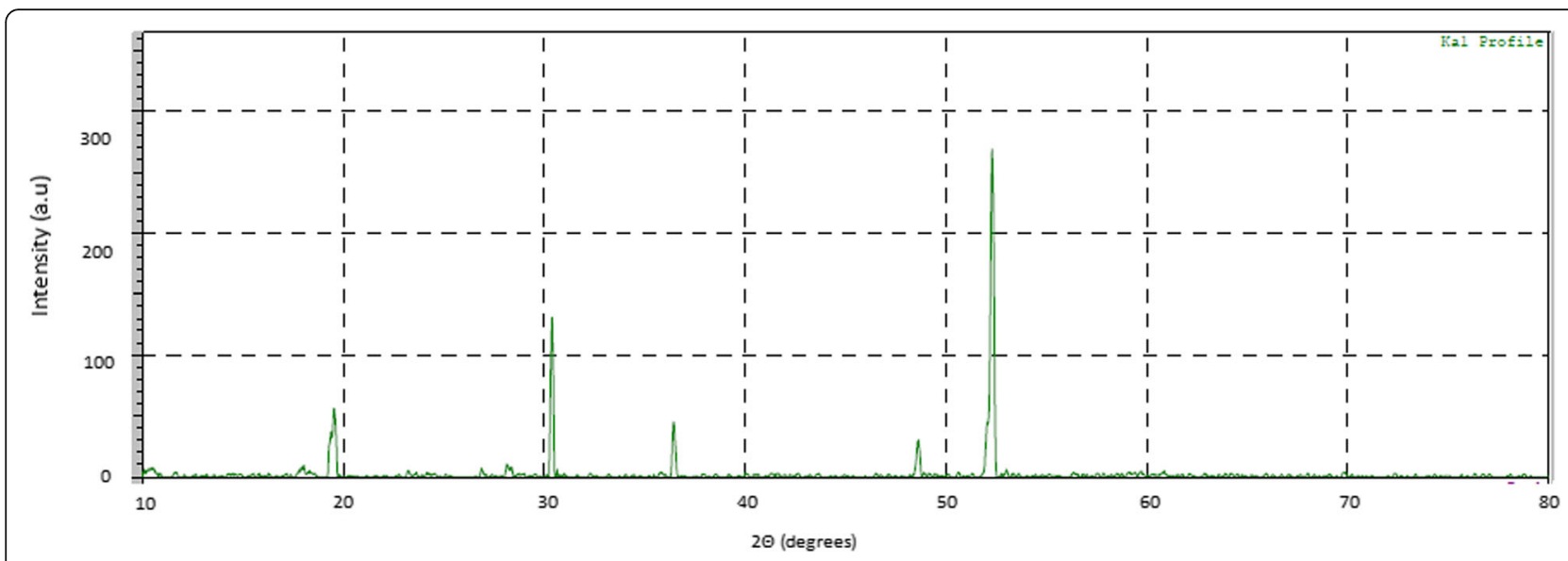

Fig. 9 XRD scan of crystals formed by $0.218 \mathrm{~g} / \mathrm{ml}$ of solute in acetone obtained by solvent evaporation method for $24 \mathrm{~h}$ with $100 \mathrm{rpm}$ stir

Table 3 shows the size of crystallite in the various crystal samples obtained by solvent evaporation method from Table 2. The $2 \theta$ value of some peaks for each sample was taken and the grain size was calculated per Debye-Scherrer formula. Table 4 shows the average size of the crystallites obtained from solvent evaporation method by using values gathered from Table 3. Tables 5 and 6 show the crystallite size and average crystallite size respectively. All the samples shown in this table were obtained by using the cooling method.

Tables 4 and 6 show that there is no apparent trend in increasing concentration of solute and crystallite size.

\section{Discussion}

The crystals obtained in methanol and acetone by solvent evaporation method are very different. In pure sulphanilamide, the powder exists in irregular shapes and the surface is fairly rough as it is seen in Fig. 10. Crystals formed in ethanol, which are much smaller, demonstrate a similar irregularity as shown in Fig. 11. However, the crystals formed in acetone and methanol are smoother, have well defined edges and are more uniform in size. It can also be seen by comparing Fig. 12 and Fig. 3 that the crystals formed in acetone, under conditions with stir, are not as well defined and are much smaller than those obtained without stirring. They are also irregular in shape and size, and have rough surfaces. In this work, the crystals formed by the cooling method are very small, irregular, and not well defined as shown in Figs. 13 and 14. The cooling method albeit being faster is more difficult to control and is more cumbersome. For observing crystal growth, the solvent evaporation method is most ideal. The selection of solvents for the crystallization process has a major impact on the results and is a crucial step in the crystallization process.

The knowledge of the influence of process conditions on the crystal growth of sulphanilamide allows one to create more efficient batch modes of purification of the solute by means of crystallization. It also allows one to carry out further work leading to spherical crystallization of the solute, as well as understanding how crystallization occurs in solvent systems having binary mixtures of solvents. As this is the initial study on the crystal growth of sulphanilamide, it gives us knowledge and guides to do further studies.

\section{Conclusion}

The crystals obtained from using methanol with high concentration of solute gave the most uniform and large-sized

Table 2 Few of the crystal samples obtained by Solvent Evaporation method

\begin{tabular}{lllr}
\hline Sample & Solvent & Concentration of sulphanilamide in $\mathrm{g} / \mathrm{ml}$ solvent & Process conditions \\
\hline A & Methanol & 0.065 & $24 \mathrm{~h}$ with no stir \\
B & Methanol & 0.065 & $48 \mathrm{~h}$ with no stir \\
C & Methanol & 0.065 & $72 \mathrm{~h} \mathrm{with} \mathrm{no} \mathrm{stir}$ \\
D & Ethanol & 0.041 & $48 \mathrm{~h} \mathrm{with} \mathrm{no} \mathrm{stir}$ \\
E & Acetone & 0.218 & $24 \mathrm{~h}$ with no stir \\
F & Acetone & 0.218 & $24 \mathrm{~h} \mathrm{with} \mathrm{stir}$ \\
\hline
\end{tabular}


Table 3 Size of crystallite obtained by solvent evaporation method from Table 2

\begin{tabular}{|c|c|c|c|}
\hline $2 \theta$ (degrees) & Fwhm (degrees) & $\cos \theta$ & Grain size (angstroms) \\
\hline \multicolumn{4}{|c|}{ Pure sulphanilamide } \\
\hline 10.186 & 0.188 & 0.996049 & 424.4599875 \\
\hline 10.4173 & 0.0853 & 0.995868 & 935.6742018 \\
\hline 18.758 & 0.1 & 0.986622 & 805.6095303 \\
\hline 20.82 & 0.1866 & 0.983527 & 433.0890347 \\
\hline 20.94 & 0.3466 & 0.983337 & 233.2083694 \\
\hline \multicolumn{4}{|l|}{ Sample A } \\
\hline 20.252 & 0.1717 & 0.984412 & 470.2494123 \\
\hline 19.98 & 0.1028 & 0.984826 & 785.09544 \\
\hline 22.5145 & 0.1671 & 0.980746 & 485.0006648 \\
\hline 21.7954 & 0.1397 & 0.981952 & 579.4131964 \\
\hline \multicolumn{4}{|l|}{ Sample B } \\
\hline 17.72 & 0.1102 & 0.988058 & 729.9800923 \\
\hline 17.9645 & 0.1287 & 0.987727 & 625.2585435 \\
\hline \multicolumn{4}{|l|}{ Sample C } \\
\hline 32.1866 & 0.4667 & 0.960782 & 177.2608226 \\
\hline 56.3 & 0.8 & 0.881626 & 112.6939721 \\
\hline 66.46 & 0.28 & 0.836355 & 339.4113798 \\
\hline 66.9392 & 0.4843 & 0.834055 & 196.7733347 \\
\hline \multicolumn{4}{|l|}{ Sample D } \\
\hline 20.1836 & 0.1518 & 0.984516 & 531.839429 \\
\hline 22.47 & 0.2031 & 0.980822 & 399.0022081 \\
\hline 41.4586 & 0.1262 & 0.935214 & 673.4493537 \\
\hline 20.76 & 0.144 & 0.983622 & 561.1572631 \\
\hline 18.7728 & 0.1571 & 0.986601 & 512.8114173 \\
\hline \multicolumn{4}{|l|}{ Sample E } \\
\hline 17.985 & 0.21 & 0.987699 & 383.2050152 \\
\hline 19.38 & 0.2044 & 0.985722 & 394.4935934 \\
\hline 19.54 & 0.218 & 0.985486 & 370.3113559 \\
\hline 28.18 & 0.2 & 0.969892 & 409.7529678 \\
\hline 30.386 & 0.1521 & 0.965022 & 541.5130387 \\
\hline 52.29 & 0.1914 & 0.897604 & 462.6454694 \\
\hline \multicolumn{4}{|l|}{ Sample F } \\
\hline 18.37 & 0.06 & 0.987168 & 1341.93917 \\
\hline 18.88 & 0.04 & 0.986448 & 2014.379473 \\
\hline 20.6966 & 0.0867 & 0.983721 & 931.9315276 \\
\hline 21.46 & 0.07 & 0.982502 & 1155.696391 \\
\hline 68.756 & 0.1687 & 0.8252 & 570.9536872 \\
\hline
\end{tabular}

Table 4 Average size of the crystallites from solvent evaporation method

\begin{tabular}{ll}
\hline Samples & Size (angstroms) \\
\hline Pure sulphanilamide & 579.9397 \\
Sample A & 677.6193 \\
Sample B & 206.5349 \\
Sample C & 535.6519 \\
Sample D & 426.9869 \\
Sample E & 1202.98 \\
Sample F & 579.9397 \\
\hline
\end{tabular}

Table 5 Crystallite size obtained using the cooling method

\begin{tabular}{lll}
\hline Sample & $2 \theta$ value (degrees) & Size (angstroms) \\
\hline $0.065 \mathrm{~g} / \mathrm{ml}$ methanol left for 4 $\mathrm{h}$ & 18.19 & 628.8749099 \\
& 18.19 & 766.6284616 \\
& 18.19 & 1609.919769 \\
$0.058 \mathrm{~g} / \mathrm{ml}$ methanol left for $6 \mathrm{~h}$ & 17.96 & 619.0021133 \\
& 18.44 & 614.2206344 \\
$0.065 \mathrm{~g} / \mathrm{ml}$ methanol left for $6 \mathrm{~h}$ & & \\
& 20.15 & 896.9890286 \\
& 18.34 & 904.6397986 \\
& 22.93 & 506.892021 \\
\hline
\end{tabular}

Table 6 Average crystallite size of samples obtained using cooling method

\begin{tabular}{ll}
\hline Conditions & Size (angstroms) \\
\hline Methanol 4 h 0.065g & 1001.808 \\
Methanol 6 h 0.058g & 616.6114 \\
Methanol 6 h 0.065g & 769.5069 \\
\hline
\end{tabular}




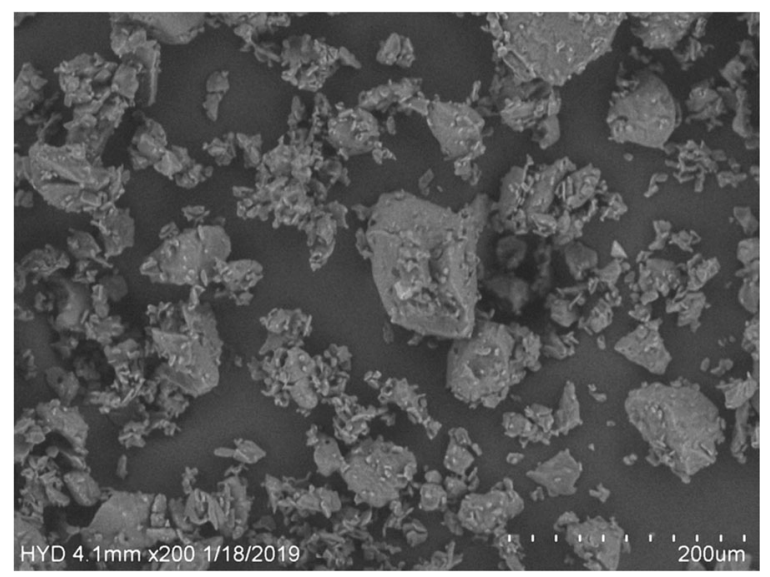

Fig. 10 SEM image of pure sulphanilamide $(\times 200)$

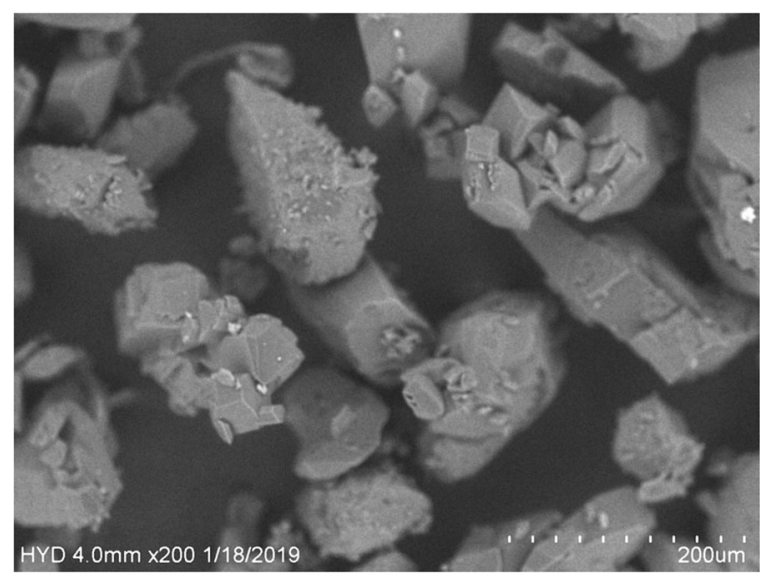

Fig. 11 SEM image of $0.041 \mathrm{~g} / \mathrm{ml}$ ethanol obtained by solvent evaporation method. Process conditions: $48 \mathrm{~h}$ without stir $(\times 200)$

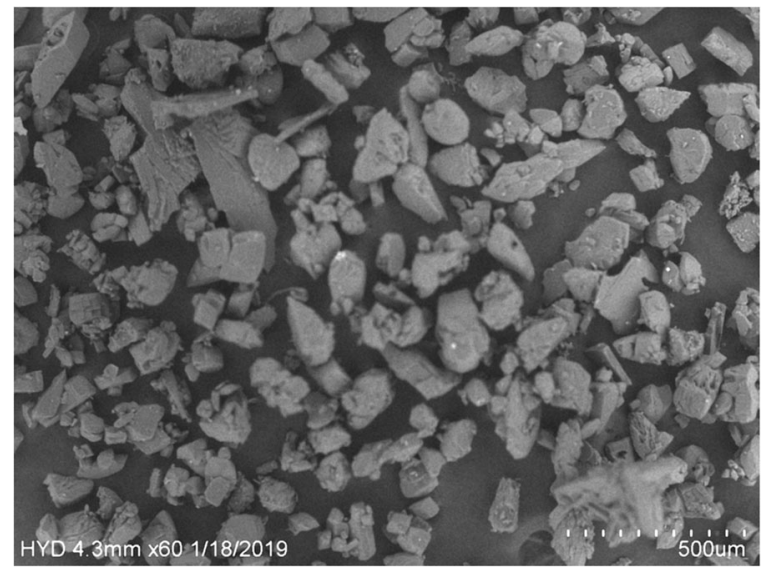

Fig. 12 SEM image of $0.218 \mathrm{~g} / \mathrm{ml}$ of solute in acetone obtained by solvent evaporation method carried out for $24 \mathrm{~h}$ with no stir $(\times 60)$

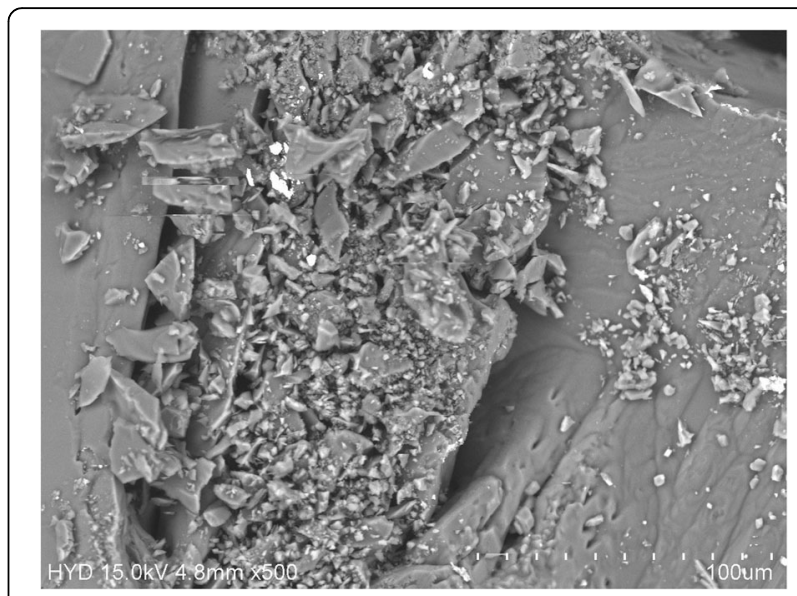

Fig. 13 SEM image of $0.058 \mathrm{~g} / \mathrm{ml}$ methanol obtained from cooling method. Process conditions: $4 \mathrm{~h}$ with no stir $(\times 500)$

cubic crystals under solvent evaporation method. The surface of the crystal was also seen to be smooth with well-defined edges as shown in the SEM images. Methanol systems need to be left for evaporation for longer periods of time to obtain larger crystals. The solvent evaporation method used with continuous stirring did not give favorable results. With acetone, the solute formed cuboidal crystals. It is preferred to use higher concentrations of solutes to get saturated solutions for this method. Acetone systems can be left for shorter time than methanol systems. Crystal formation is not favorable in ethanol systems. The cooling method is not suitable to get uniform crystals. The XRD analysis of crystals was carried out along with DSC of the crystals. Data on the melting characteristics was obtained from DSC and crystallite size was obtained using Debye-Scherrer formula. The parameters were compared for both the methods-cooling method and solvent evaporation method.

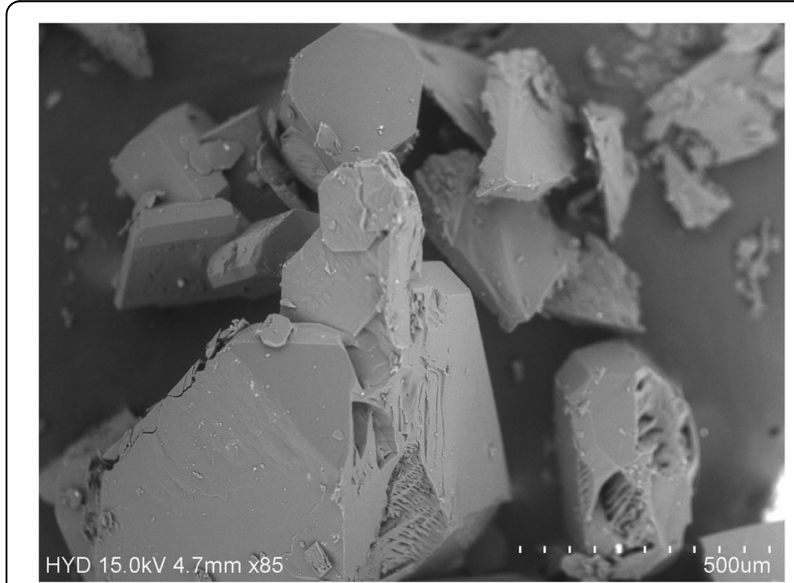

Fig. 14 SEM image of $0.065 \mathrm{~g} / \mathrm{ml}$ methanol obtained from cooling method. Process conditions: $6 \mathrm{~h}$ with no stir $(\times 85)$ 


\section{Abbreviations}

XRD: X-ray diffraction; DSC: Differential scanning calorimetry; SEM: Scanning electron microscopy

\section{Acknowledgements}

The authors would like to express their gratefulness to everyone who supported them throughout the course of this project, especially Prof. Shyam Sunder R. UCT, OU, and for allowing us to use central analytical facility. We would like to thank Mr. Sammaiah for helping in analysis.

\section{Authors' contributions}

JT conceived of the presented idea and designed the plan of experiments. SSD collected the data and samples. JT and SSD analyzed the data and interpreted the results. SSD drafted the article in consultation with JT. AKT supervised SSD. All authors gave their individual critical revision and final approval of the version to be submitted.

\section{Funding}

Not applicable

\section{Availability of data and materials}

All data and material are available upon request.

Ethics approval and consent to participate

Not applicable

\section{Consent for publication}

Not applicable

\section{Competing interests}

The authors declare that they have no competing interests.

Received: 16 April 2020 Accepted: 12 August 2020

Published online: 10 September 2020

\section{References}

1. Katta J, Rasmuson ÅC (2007) Spherical crystallization of benzoic acid. Int J of Pharm. 348(1-2):61-69

2. Ames Laboratory (2017). The power of one: Single crystals provide clarity. ScienceDaily. http://www.sciencedaily.com/releases/2017/03/170327143513. htm. Accessed 13 Jan 2020.

3. Göran Alderborn and Christer Nyström(eds)(1996). Pharmaceutical powder compaction technology. J. Nat. Prod. 59(8):822-822.

4. Goldberger J, He R, Zhang (2003) Single-crystal gallium nitride nanotubes, Nature 422(599-602). https://doi.org/10.1038/nature01551.

5. Xue D, Sun C (2017) Crystallization: a phase transition process driving by chemical potential decrease. J of Crystal Growth 740(27-32)

6. National Center for Biotechnology Information. PubChem Database Sulfanilamide, $C I D=5333$. https://pubchem.ncbinlm.nih.gov/compound/ Sulfanilamide. Accessed on 3 Jan 2020.

7. Aisling L, Åke R (2019) Crystal growth of single salicylamide crystals. Cryst. Growth Des. 19(12):7230-7239. https://doi.org/10.1021/acs.cgd.9b01101

8. Bausch A, Leuenberger $\mathrm{H}$ (1994) Wet spherical agglomeration of proteins as a new method to prepare parenteral fast soluble dosage forms. Int J of Pharm. 101(63-70)

\section{Publisher's Note}

Springer Nature remains neutral with regard to jurisdictional claims in published maps and institutional affiliations.

\section{Submit your manuscript to a SpringerOpen ${ }^{\circ}$ journal and benefit from:}

- Convenient online submission

- Rigorous peer review

- Open access: articles freely available online

High visibility within the field

- Retaining the copyright to your article

Submit your next manuscript at $\boldsymbol{\nabla}$ springeropen.com 